\title{
Analysis of discard process and recycle of glass on a drink distributor at Manaus, Amazonas
}

\section{Fabiane Amaral de Albuquerque Silva ${ }^{1}$, Marcelo Oliveira Lima ${ }^{1}$, Claudio Nahum Alves ${ }^{1}$}

\begin{abstract}
1, Programa de Pós-Graduação em Ciência e Meio Ambiente do Instituto de Ciências Exatas e Naturais da Universidade Federal do Pará (PPGCMA/ICEN/UFPA). Bairro Guamá. CEP: 66075-110. Caixa Postal 479. PABX +55 913201 7000. Belém - Pará - Brasil.
\end{abstract}

Email: fabiane-albuquerque@bol.com.br

Received: September 11 $11^{\text {th }}, 2017$.

Accepted: September $25^{\text {th }}, 2017$.

Published: September 30th 2017.

Copyright (C2016 by authors and Institute of Technology Galileo of Amazon (ITEGAM) This work is licensed under the Creative Commons Attribution International License (CC BY 4.0).

http://creativecommons.org/licenses/by/4.0/ (c) (i) (3)(2) Open Actes:

\section{ABSTRACT}

Public politics around the world are in development by different organizations, such as United Nations (UN), to preserve the environment and help people to be aware about recycling process. Instead, a common problem is the improper discard of many dejects that are set free into the environment, causing many problems of public health, beyond acting as a reservoir for many other social and environmental complications. Nowadays many governmental measures have been used to provide more knowledge about the consequences of glass improper discard, once this is the major material on drink commerce, also for being too fragile and hard to control the inadequate discard. With it, this study aims evaluate the firms located at the Industrial District which composed the Study to Development of an Integrated Solution Related to Industry Waste Management at Industrial Pole of Manaus. Still, we also evaluated the discard of a drink distributor of Manaus city looking for a better knowledge to future and higher studies. We selected randomly a small port distributor, which we saw that the glass' major destiny is to recycle, using a tertiary firm to complete this process. Yet, we found out that the period of daily work is around 10h to the employees, which receive trainings every two months by the own firm. So, we concluded that the firm acts with major concern about environmental pollution, looking for avoiding it.

Keywords: Environment; glass; awareness.

\begin{abstract}
Análise do processo de descarte e reciclagem de vidro em uma distribuidora de bebidas da cidade de Manaus, estado do Amazonas

RESUMO

Políticas públicas ao redor do mundo vêm sendo desenvolvidas por organizações, principalmente pela Organização das Nações Unidas (ONU), para preservar o meio ambiente e conscientizar as pessoas sob a importância da reciclagem. No entanto, um problema recorrente é o descarte indevido de vários dejetos que são liberados no meio ambiente erroneamente, causando assim, vários problemas de saúde pública, além de servirem de reservatório para vários outras complicações sociais e ambientais. Atualmente várias medidas governamentais vêm sendo utilizadas para proporcionar mais conhecimento acerca das consequências do descarte indevido de vidro, uma vez que este material é um dos principais no comércio de bebidas, além de ser quebradiço e difícil de controlar o descarte devido. Com isso, esse projeto propõe avaliar o as empresas do Distrito Industrial que compuseram o Estudo para o Desenvolvimento de uma Solução Integrada Relativa à Gestão de Resíduos Industriais no Pólo Industrial de Manaus. Ainda, também foi avaliado o descarte de uma distribuidora de bebidas da cidade de Manaus visando ter um conhecimento para estudos futuros de maior espectro. Foi selecionada de modo aleatório uma distribuidora de Manaus de pequeno porte, onde foi visto que o destino do vidro que é descartado é a reciclagem, sendo contatada uma empresa terciária para realizar a reciclagem. Ainda, foi visto que o período de trabalho é de 10 horas por dia para os funcionários, recebendo estes, treinamento a cada dois meses fornecido pela própria empresa. Então, foi observado que a empresa atua nos padrões, com intensa preocupação na contaminação ambiental, procurando evita-la.
\end{abstract}

Palavras-chave: Meio ambiente; vidro; conscientização. 


\section{INTRODUÇÃO}

A produção de materiais pela indústria é um importante marco para a economia do local. $\mathrm{O}$ setor industriário compõe grande parte da sociedade, seja através de meios sociológicos com a disponibilidade de emprego, como a alta produtividade de materiais e serviços que atendem tanto a nível estadual, como nacional e internacional em alguns casos.

Dessa forma, os materiais produzidos e distribuídos por empresas de bebidas vêm obtendo maior distribuição geográfica devido ao mercado consumista, e como consequência, a poluição ambiental vem aumentando. Sendo este um importante problema de saúde pública e ambiental por implicar direta ou indiretamente na contaminação de espaços públicos, como afluentes e suas nascentes, atuando negativamente na flora e na fauna aos arredores destes espaços [3].

Um dos grandes problemas que a gestão ambiental vem enfrentado é justamente o descarte de resíduos no meio ambiente, que por sua vez, estão relacionados a enfermidades no homem, seja por meio de vetores, ou agentes etiológicos, conforme observado nos países com saneamento básico precário ou ausente [1] [10].

Embora políticas públicas tenham sido criadas visando a redução da taxa de poluição, os materiais mais prejudiciais ao ambiente são os resíduos sólidos produzidos pelas empresas, mas que estas não os reavêm para reciclagem devido à negligência da população quanto à saúde ambiental. Essas políticas, associada à conscientização é uma proposta com possibilidade de sucesso.

Os materiais mais preocupantes e prejudiciais, no viés ambiental, são os resíduos sólidos, sendo o plástico e o vidro os principais [8]. Mundialmente o vidro representa 7,5\% de todo o resíduo doméstico que é descartado anualmente enquanto a nível nacional, existe um consumo anual de $5,57 \mathrm{~kg}$ de vidro por habitante [4]

Estudos acerca dos impactos vítreos e a gestão empresarial das distribuidoras de bebidas da cidade de Manaus-AM sobre o meio ambiente ainda são escassos, salientando a importância do nosso trabalho, visto que o Amazonas abriga grande parte da floresta Amazônica.

\section{REVISÃO BIBLIOGRÁFICA}

\section{II.1 MEIO AMBIENTE}

Entende-se que meio ambiente é a junção do ambiente físico e seus componentes bióticos, englobando um conjunto de ecossistemas, cujos animais e outros organismos interrelacionam entre si [9].

Por Meio Ambiente, entende-se como o espaço e o tempo entre as interações dos organismos vivos e não vivos [7]. Devido a isso, políticas públicas vêm sendo desenvolvidas, ao redor do mundo, para preservação do meio ambiente e conscientização do ser humano sob sua importância, uma vez que o meio ambiente é o habitat social e fonte de auto sustentabilidade da vida na terra [12].

\section{II.2 RESÍDUOS SÓLIDOS}

De acordo com a Política Nacional de Resíduos Sólidos [5], resíduos sólidos é todo objeto, substância, material, ou bem descartado advindo de atividades humanas em sociedade, e cujo direcionamento final ocorre nos estados semissólido ou sólido, bem como gases contidos em recipientes e líquidos cujas especificidades são impróprias para o seu lançamento na rede pública de esgotos ou em afluentes, ou que para isso se faz necessário soluções técnicas ou economicamente inexequíveis em face da melhor tecnologia disponível. Com um amplo uso social, existem várias utilidades em diferentes áreas.

\section{II.3 DESCARTE DE RESÍDUOS}

O descarte de resíduos sólidos no Brasil, é realizado através de três fases: coleta, transporte e disposição. Porém, verifica-se uma diferença significativa quando divide-se a população em duas massas: Rural e Urbana. Foi observado que a zona rural possui uma maior desorganização do lixo, pois não há monitoramento e os indivíduos da região já se habituaramse ao convívio com o material próximo às suas residências [10].

No estado do Amazonas, não há nenhum aterro sanitário (o mais indicado para descarte de resíduos), sendo apenas a cidade de Manaus a detentora de um aterro controlado [14].

Foi observado que os habitantes de Manaus têm consciência do significado de lixo, declarando que lixo é "aquilo que não tem mais utilidade", enquanto $10 \%$ dos entrevistados declararam não ter conhecimento do significado de resíduo [12].

\section{II.4 VIDRO}

Entende-se por vidro, uma substância homogênea composta $72 \%$ de sílica ( $\mathrm{SiO} 2$ ), 14\% de sódio (Na2SO4), 9\% de Cálcio $(\mathrm{CaO}), 4 \%$ de Magnésio $(\mathrm{MgO}), 0,7 \%$ de alumina (A12O3) e 0,3\% de Potássio (K2O) sem coloração, rígido e resistente a impactos mesclado por uma rede de sílica com moléculas ligadas de modo tridimensional, formando um tetraedro silício-oxigênio [2].

A utilização do vidro é ampla, abrangendo desde grandes áreas, como janelas e muros, até o uso em objetos domésticos, como taças e copos. O vidro é também muito utilizado por parte da ciência devido a sua disposição em permitir a passagem de luz sem modificar a visualização.

\section{5 DESCARTE DE VIDRO}

Bem como é amplamente empregado com diversas utilidades, principalmente por empresas de bebidas, alimentos, medicamentos e perfumes, sua reciclagem é fundamental, uma vez que o Brasil produz aproximadamente 980 mil toneladas de vidro por ano [6].

\section{6 RECICLAGEM NO BRASIL}

No Brasil, os resíduos sólidos são considerados muito heterogêneos, pois possuem componentes orgânicos e inorgânicos, além de ampla variação utilitária, com base na população presente em cada residência.

Entende-se desta forma que uma das maiores preocupações ambientais é o correto descarte desses tipos de resíduos, levando-se em considerações primordiais o descarte do plástico, do metal, do vidro, do papel ou dos elementos orgânicos. O descarte incorreto é um problema social e ambiental que influencia nos ecossistemas aquáticos, florestais 
e ambientais, tendo como maior agravante a falta de coleta de lixo, associado ao hábito pouco frequente ou quase nenhum, do brasileiro de descartar corretamente o lixo produzido no dia a dia, descartando-o em ruas, avenidas e corpos d'água, contribuindo de forma significativa para danificar o meio ambiente [12].

É comprovada que a separação incorreta, ou a ausência total de separação dos resíduos pode levar a dificuldades na reciclagem, além disso, o descarte em conjunto de materiais radioativos, como pilhas e aparelhos eletrônicos podem acabar danificando a qualidade do composto orgânico, como plástico e vidro.

\section{II.7 RECICLAGEM EM MANAUS}

Existe uma alta produção de resíduos sólidos na cidade de Manaus, porém não há relatos na cidade sobre um local correto para descarte destes resíduos. Além da falta de aterros sanitários no Amazonas (havendo apenas um aterro controlado), junto com o alumínio e vidro sendo os principais componentes da poluição ambiental na região, faz-se importante a falta de reciclagem e descarte correto de resíduos sólidos na cidade [13].

A Zona Franca de Manaus (ZFM) é localizada no pólo industrial da cidade possuindo três polos econômicos comercial, industrial e agropecuário. Destes, o setor industrial é o maior até hoje, abrigando cerca de 600 empresas nacionais e internacionais que geram emprego à população e renda ao Estado.

Dentro das áreas de produção, o vidro é amplamente utilizado, sendo as indústrias relacionadas à produção de utensílio e bebidas da ZFM as principais utilizadoras de produtos que possuem o vidro como matéria-prima na cidade de Manaus.

\section{MATERIAIS E MÉTODOS}

Esta foi uma pesquisa de caráter observacional, descritivo e transversal, avaliando o relatório "Estudo para o Desenvolvimento de uma Solução Integrada Relativa à Gestão de Resíduos Industriais no Pólo Industrial de Manaus" sobre empresas da ZMF utilizando-o como padrão para caracterizar uma distribuidora de bebidas da cidade de Manaus.

Foi selecionada uma empresa cujo comércio de bebidas seja o principal meio de renda, dessa forma, utilizando o vidro como principal recipiente para armazenamento e transporte de bebidas. Assim, a empresa Norte Representações e Comércio de Alimentos se mostrou apta à avaliação das suas condições de descarte de vidro e outros resíduos.

Os dados utilizados para comparação foram: Tipo de reciclagem e descarte, localização da empresa, número de funcionários presença de licença ambiental, ano de abertura da empresa, área de ocupação da empresa, carga horária funcional e o treinamento dos funcionários sobre gestão de resíduos. Esses parâmetros foram selecionados conforme descritos pelo relatório da ZFM e utilizados para caracterizar a empresa Norte Representações e Comércio de Alimentos, visando eventual comparação entre a produção e descarte vítreo de empresas da ZFM e outra empresa que não pertence à ZFM.

Os dados obtidos foram tabulados e analisados pelo programa Microsoft Excel 2010, assim como a construção de gráficos e tabelas.

\section{RESULTADOS E DISCUSSÕES}

Foram encontradas 90 empresas dentro do relatório da ZFM, onde $64 \%$ realizam métodos de reciclagem, como uso do forno industrial, caldeiras, forno de cimento e reciclagem, enquanto $23 \%$ não tem retorno do lixo, sendo este levado a lixões particulares, infiltrações no solo e rede de esgoto e apenas $13 \%$ realizam o tratamento dos materiais descartados.

Os dados coletados das empresas da ZFM estão distribuídas na tabela 1 , onde observa-se que grande parte das empresas da ZFM estão localizadas fora do Distrito Industrial, mas ainda dentro da cidade de Manaus tendo em média menos de 10 funcionários

É notório que $74 \%$ tem licença ambiental, mesmo com menos de 17 anos no mercado, ocupando principalmente uma área entre 1.000 e $10.000 \mathrm{~m}^{2}$, com carga horária de trabalho entre $8 \mathrm{~h}$ e $16 \mathrm{~h}$, havendo o treinamento dos funcionários sobre gestão ambiental.

Das empresas que compõem as 90 da ZFM, algumas não constataram no relatório todos os parâmetros de análise.

Em relação à empresa analisada, foi observado que o vidro compõe $46 \%$ do material utilizado pela empresa, além disso, $78 \%$ dos materiais produzidos e descartados são reciclados, seguido por $18 \%$ que vão atuar como matéria-prima para materiais da prefeitura e apenas $4 \%$ é destinado ao aterro. Para reciclagem, a empresa entra em contato com terceirizados especialistas em reciclagem, evitando a contaminação ambiental. Para os $4 \%$ que vão para o aterro, trata-se de uma estimativa da empresa, já que dentro deste parâmetro estão aqueles materiais que a empresa envia (o mínimo, conforme relatado), assim como aqueles que não retornam à empresa para que esta faça o devido processo de reciclagem, sendo por isso, o aterro considerado o destino final desses produtos.

Quanto aos parâmetros de comparação, foi constatado que a empresa detêm de 10 a 50 funcionários que trabalham de 8 a 16 horas por dia por ser nova no mercado, fundada em 2014, obtendo no entanto, bons resultados quanto à comercialização de bebidas em Manaus com uma área atual de $1.000 \mathrm{~m} 2$, havendo pretensão de expansão em breve.

Não foi constatada presença de licença ambiental, entretanto, foi alegado haver treinamento dos funcionários a cada dois meses visando aprimorar o conhecimento empresarial voltado para novas opções de descarte, reciclagem e reutilização de resíduos sólidos (principalmente vidro e plástico).

A tabela 1 mostra a comparação dos resultados obtidos pelas empresas avaliadas no relatório com a Norte Representações e Comércio de Alimentos, enquanto o gráfico 1 mostra a proporção do uso do vidro, compara ao seu descarte, distribuído por semestre desde 2014 até o final de 2015. 
Tabela: Comparação das 90 empresas do relatório da ZFM com a Norte Representações e Comércio de Alimentos.

\begin{tabular}{|c|c|c|}
\hline Parâmetros de avaliação & Empresas do Relatório & $\begin{array}{c}\text { Norte Representações e Comércio de } \\
\text { Alimentos }\end{array}$ \\
\hline \multicolumn{3}{|l|}{ Localização } \\
\hline DI1 & 15 & - \\
\hline DI2 & 13 & - \\
\hline Fora do DI (dentro de Manaus) & 59 & + \\
\hline Fora de Manaus & 3 & - \\
\hline \multicolumn{3}{|l|}{ Número de Funcionários } \\
\hline$<10$ & 32 & - \\
\hline $10-50$ & 29 & + \\
\hline $50-100$ & 7 & - \\
\hline$>100$ & 9 & - \\
\hline Sem registro & 13 & - \\
\hline \multicolumn{3}{|l|}{ Licença Ambiental } \\
\hline Sim & 67 & - \\
\hline Não & 23 & + \\
\hline \multicolumn{3}{|l|}{ Ano de abertura da empresa } \\
\hline Antes de 1990 & 21 & - \\
\hline $1999-2000$ & 19 & - \\
\hline Após 2000 & 46 & + \\
\hline Sem registro & 4 & - \\
\hline \multicolumn{3}{|l|}{ Área Total (m2) } \\
\hline$<1.000$ & 28 & + \\
\hline $1.000-10.000$ & 31 & - \\
\hline 10.000 & 24 & - \\
\hline Sem registro & 7 & - \\
\hline \multicolumn{3}{|l|}{ Carga horária } \\
\hline$<8 \mathrm{~h}$ & 2 & - \\
\hline $8-16 h$ & 76 & + \\
\hline $16-24 h$ & 11 & - \\
\hline Sem registro & 1 & - \\
\hline \multicolumn{3}{|l|}{ Treinamento dos funcionários } \\
\hline Sim & 80 & + \\
\hline Não & 10 & - \\
\hline
\end{tabular}

Fonte: Autores, (2017). 


\section{Proporção do vidro utilizado e descartado}

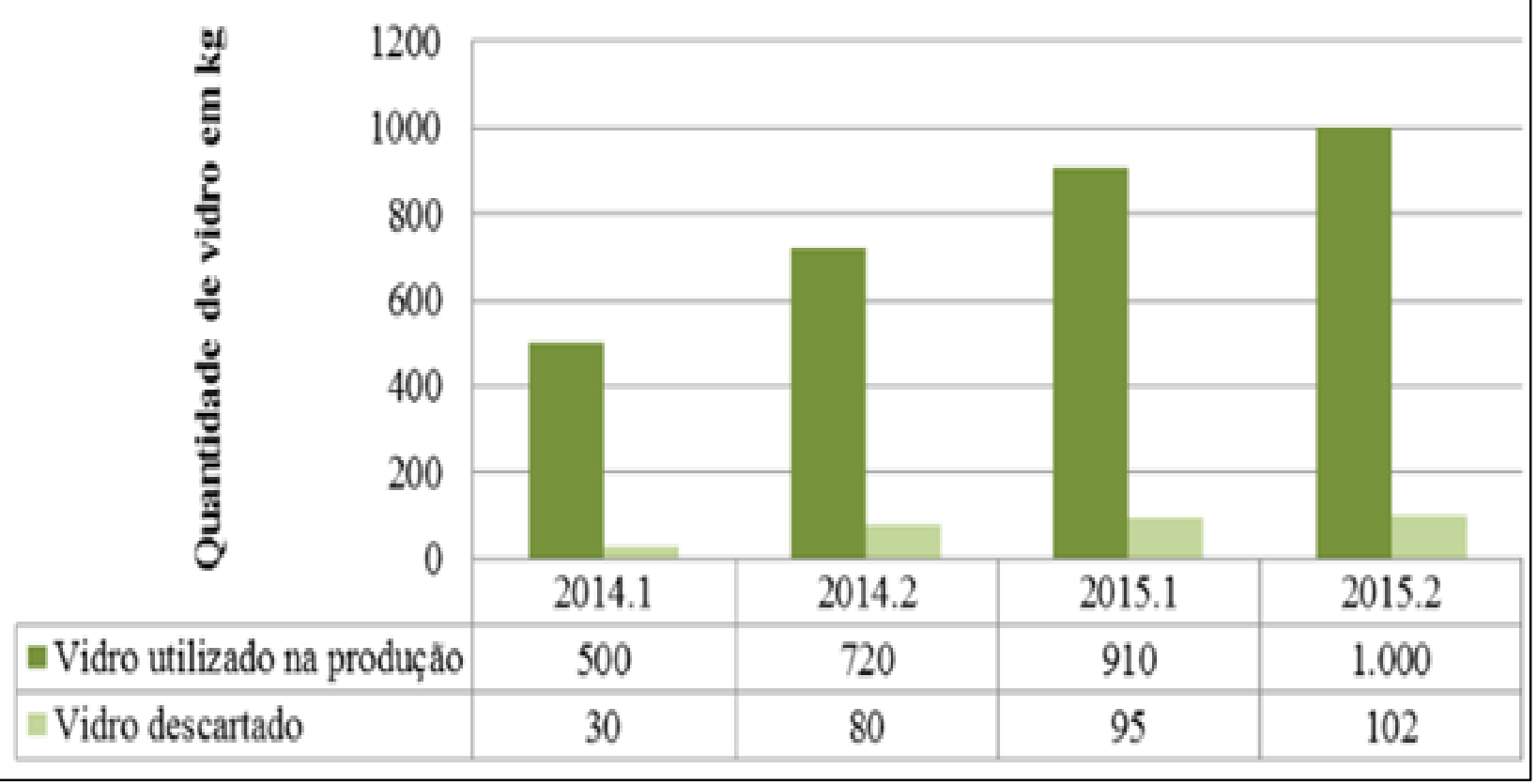

Gráfico 1: Quantidade de vidro produzido e descartado no período de 2014 a 2015.

Fonte: Autores, 2017.

\section{CONCLUSÃO}

Embora o método de descarte mais eficiente seja por meio de aterro sanitário [13], o estado do Amazonas possui apenas um aterro controlado, havendo outros meios de descarte de lixo, como a reciclagem, um método viável, sustentável e menos danoso ao ambiente.

Outro ponto a ser avaliado é o aumento populacional que está diretamente relacionado ao alto consumo de produtos vindos da ZFM. Consequentemente, a produção de resíduos também tende a aumentar, havendo maior poluição ambiental caso o lixo não seja devidamente descartado.

Foi observado que muitas das empresas estão localizadas dentro o perímetro da cidade, mas fora do Distrito Industrial, assim como a empresa analisada. A este fato atribui-se maior custo às empresas para transporte e descarte dos resíduos.

Quanto ao número de funcionários, alega-se que está diretamente proporcional à produção. Assim, embora o lucro aumente, estima-se que a contaminação ambiental também cresça e por isso, medidas de fiscalização se fazem necessárias em algumas empresas. Ainda, a jornada de trabalho é a mesma que as empresas da ZFM, permitindo a comparação de outro parâmetros em associação com a influência da poluição ambiental.

Voltando para a presença de licença ambiental, foi constatado no relatório que apenas as empresas que podem causar algum dano ao meio ambiente precisam de licença. A Norte Representações e Comércio de Alimentos não possui licença, mas por já ter dado início à documentação e treinar os funcionários constantemente, os índices de poluição não são altos.

Por ser nova no mercado, a produção de resíduos da Norte Representações e Comércio de Alimentos não tem muita influência na poluição geral, principalmente por ser uma empresa de pequeno porte, com menos de $1.000 \mathrm{~m} 2$.

\section{AGRADECIMENTOS}

Ao PPGCMA/ICEN/UFPA, ao ITEGAM e à SUFRAMA pelo apoio a pesquisa.

\section{REFERÊNCIAS}

[1] Abbas, A. K.; Lichtman, A. H.; Pillai, S. Imunologia Celular e Molecular. [s.l: s.n.].

[2] Akerman, M. Natureza , Estrutura e Propriedades do Vidro. CETEV, p. 1-37, 2000.

[3] Amâncio, C. T.; Nascimento, L. F. C. Asma e poluentes ambientais : um estudo de séries temporais. Revista da Associação Médica Brasileira, v. 58, n. 3, p. 302-307, 2012.

[4] Assis, O. B. G. O uso de vidro reciclado na confecção de membranas para microfiltração. Ceramica, v. 52, n. 321, p. 105-113, 2006.

[5] Brasil. Política Nacional dos Resíduos Sólidos. 2. ed. 2012.

[6] Cempre. Vidro. Disponível em: <http://cempre.org.br/artigopublicacao/ficha-tecnica/id/6/vidro>. Acesso em: 4 out. 2016.

[7] Dulley, R. D. Noção de natureza, ambiente, meio ambiente, recursos ambientais e recursos naturais. Agricultura em São Paulo, v. 51, n. 2, p. 15-26, 2004. 
[8] Cocco, I. R. et al. Reaproveitamento de materiais não degradáveis no reparo de coberturas: vidro, isopor e embalagens tetra pak. XVI Seminário Interinstitucional de Ensino, Pesquisa e Extensão, p. 1-5, 2011.

[9] Grisi, B. M. Glossário de Ecologia e Ciências Ambientais. [s.l: s.n.].

[10] Leite, M. A. et al. Estimativa do descarte de resíduos passíveis de reciclagem na área rural de ilha solteira-sp. Brazilian Journal of Biosystems Engineering, v. 8, n. 4, p. 324-332, 2014.

[11] Oliveira, K. C.; Santos, R. M. DA S.; Viana, Á. L. Geração de resíduos sólidos: a percepção da população em um bairro da Cidade de Manaus, Amazonas. InterfacEHS - Saúde, Meio Ambiente e Sustentabilidade, v. 11, n. 1, p. 42-52, 2016.

[12] Oliveira, M. C. B. R. DE. Gestão de resíduos plásticos pós-consumo: perspectivas para a reciclagem no Brasil. 2012. Pós-Graduação e Pesquisa de Engenharia - COPPE, Universidade Federal do Rio de Janeiro, Rio de Janeiro. 2012.

[13] ONU. A ONU e o meio ambiente. Disponível em: <https://nacoesunidas.org/acao/meio-ambiente/>. Acesso em: 4 out. 2016.

[14] Pereira, R. G. et al. Os desafios rumo à destinação sustentável dos resíduos sólidos recicláveis na comunidade Nossa Senhora de Fátima, Tarumã Mirim, Rio Negro, Manaus. PCE - Programa Ciência na Escola, v. 3, n. 1, p. 32-36, 2015. 